\title{
UK Renal Registry 16th Annual Report: Chapter 11 Blood Pressure Profile of Prevalent Patients receiving Renal Replacement Therapy in 2012: National and Centre-specific Analyses
}

\author{
Anirudh Rao ${ }^{a}$, David Pitcher ${ }^{a}$, Ken Farrington ${ }^{b}$ \\ aUK Renal Registry, Bristol, UK; ' ${ }^{\mathrm{a}}$ Lister Hospital, Stevenage, UK
}

\section{Key Words}

Diastolic blood pressure - Epidemiology - Established renal failure - Haemodialysis - Peritoneal dialysis - Pulse pressure - Systolic blood pressure - Transplant

\footnotetext{
Abstract

Introduction: There continues to be uncertainty in the literature about which blood pressure (BP) recordings in which time period associate best with long-term patient outcomes and therefore optimal target ranges. Methods: Patients receiving renal replacement therapy (RRT) on 31st December 2012 with a BP reading in either the fourth or third quarter of 2012 were included. Summary statistics were calculated for each renal centre and country. Results: Data completeness for BP measurements submitted to the
}

UK Renal Registry (UKRR) for all modalities were improved from previous years: it was better for haemodialysis (HD) patients ( $75 \%$ for pre-HD measurements) than for peritoneal dialysis (PD) patients (51\%) or transplant recipients (41\%). In 2012, the median pre- and post-HD systolic blood pressures (SBPs) were $140 \mathrm{mmHg}$ and $128 \mathrm{mmHg}$ respectively. The median SBP of patients on PD was $137 \mathrm{mmHg}$. Transplant recipients had a median SBP of $134 \mathrm{mmHg}$. Median diastolic blood pressures (DBPs) were $71 \mathrm{mmHg}$ (pre-HD), $67 \mathrm{mmHg}$ (post-HD), $78 \mathrm{mmHg}(\mathrm{PD})$ and $79 \mathrm{mmHg}$ (transplant). Only $26 \%$ of $\mathrm{PD}$ patients achieved the Renal Association guideline of SBP $<130 \mathrm{mmHg}$ and DBP $<80 \mathrm{mmHg}$. Amongst transplant patients, 27\% achieved the Renal Association guideline of SBP $<130 \mathrm{mmHg}$ and DBP $<80 \mathrm{mmHg}$. Conclusion: In 2012 there continued to be significant variation in the achievement of BP standards between UK renal centres.

$\begin{array}{ll}\text { KARGER } & \text { C 2014 S. Karger AG, Basel } \\ \begin{array}{l}\text { Fax +4161306 1234 } \\ \text { E-Mail karger@karger.com } \\ \text { www.karger.com }\end{array} & \begin{array}{l}\text { Accessible online at: } \\ \text { www.karger.com/nec }\end{array}\end{array}$

Email: renalregistry@renalregistry.nhs.uk 


\section{Introduction}

The aetiology of hypertension in established renal failure is multifactorial and interpreting blood pressure (BP) values in this cohort of patients is challenging. In dialysis patients there is a complex interplay between volume overload with salt (and water) which may be appropriately addressed by dialysis, and vasoconstriction caused by neurohumoral mechanisms which may require additional treatment with antihypertensive drugs. These mechanisms lead to cardiovascular dysfunction and may be important in the observation of the ' $U$-shaped' mortality curve seen in relation to BP in dialysis patients $[1,2]$. Original descriptions at the individual patient level were confounded by unmeasured case-mix, with comorbidity associated with both lower BP and lower survival. Similar patterns have now been reported at centre level [3]. It is possible that the association can be overcome by longer or more frequent sessions of dialysis and careful attention to dry-weight $[4,5]$. Iatrogenic factors such as erythropoiesis stimulating agents (ESA) [6] in dialysis patients and ciclosporin [7] in transplant patients may also contribute to high BP. Further, BP in dialysis patients varies as much within individuals as it does between individuals [8]. The extent of this variability appears to be as important as the absolute value in predicting cardiovascular mortality in haemodialysis patients [9]. The optimal measure of BP therefore remains the subject of considerable controversy, with ambulatory $\mathrm{BP}$ predicting mortality better than pre- or post-dialysis BP [10]. There is some evidence to suggest that pre-dialysis systolic blood pressures (SBPs) >150-160 [11-13] are associated with excess mortality in haemodialysis patients and other data suggesting that very high SBP $(>200)$ pre-dialysis seems to confer an adverse prognosis [14]. Conversely, lowering BP too aggressively may lead to intradialytic hypotension [15], which is an independent predictor of mortality $[16,17]$. Data from a number of studies suggest excess mortality associated with predialysis $\mathrm{SBP}<120 \mathrm{mmHg}[14,18]$.

The Renal Association guidelines updated in August 2010 and in operation during the period in which the audit data in this chapter were collected [19] stated:

Guideline 5.2 - CVD: Hypertension in dialysis patients

We suggest that pre- and post-dialysis blood pressure (measured after completion of dialysis, including washback) should be recorded and intra-dialytic blood pressure measurements should be made to facilitate good management of the HD session. (2D)

Guideline 5.4 - CVD: Hypertension in dialysis patients

It would be sensible to avoid sustained BP extremes and, in order to try to provide some guidance we suggest that systolic blood pressure during the inter-dialytic period on HD and for PD patients should not regularly exceed $>160 \mathrm{mmHg}$. (2C)

Guideline 5.5 - CVD: Hypotension/Hypertension in dialysis patients

We suggest that systolic blood pressure should not routinely be treated with pharmacological agents with antihypertensive properties if SBP is regularly $<120 \mathrm{mmHg}$ pre dialysis.

Guideline 5.7 - CVD: Hypertension in dialysis patients

We suggest that hypertension on dialysis should be managed by ultrafiltration in the first instance. (2D)

Blood pressure in peritoneal dialysis patients should be $<130 / 80 \mathrm{mmHg}$ (Good Practice).

The target blood pressure for renal transplant patients is $<130 / 80 \mathrm{mmHg}$ (Good practice).

These guidelines are consistent with international guidelines [20, 21].

This chapter reports UK Renal Registry (UKRR) data completeness for BP for adult renal centres in England, Northern Ireland and Wales and presents centre level average BP attainment for patients on haemodialysis (HD), peritoneal dialysis (PD) and with a functioning kidney transplant at the end of December 2012.

\section{Methods}

All adult patients in England, Wales and Northern Ireland receiving renal replacement therapy (RRT) (HD, PD and transplant recipients) on 31st December 2012 were considered for inclusion in the analyses.

The method of data extraction employed is described in chapter 15 of the 11th UKRR Annual Report [22]. The UKRR extracts quarterly laboratory, clinical and demographic data for all patients receiving RRT in the 62 renal centres in England, Northern Ireland and Wales. Data on some variables from the nine Scottish renal centres are sent annually to the Scottish Renal Registry. However, BP measurements are only collected from the Scottish Registry 
for $\mathrm{HD}$ patients and therefore PD and transplant patients from Scottish renal centres are excluded from all BP analyses.

Patients who had been on the same modality and at the same renal centre for three months and with a valid BP reading in either the fourth or the third quarter of 2012 were included. This included incident patients starting RRT during 2012 who were still alive on 31st December 2012. Analyses used the last recorded BP from quarter four, however, if this was missing, the last recorded BP from quarter three was used instead. BP data from quarter two were used for patients at renal centres in Scotland because BP data from quarters three and four were unavailable.

Analyses were performed for each RRT modality (HD, PD and transplant). Most UK renal centres manage $\mathrm{HD}, \mathrm{PD}$ and transplant patients. However, Colchester had no PD patients and four centres (Bangor, Colchester, Liverpool Aintree, Wirral) had no transplant patients under their care.

All patients meeting the criteria above were included in the overall national analyses, but renal centres with less than $50 \%$ data completeness for any modality, or fewer than 20 patients with results, were excluded from the centre level analysis for that modality. The number preceding the centre name in each figure corresponds to the percentage of missing data for that centre.

Patients on HD were analysed both by pre-dialysis and postdialysis BP. The BP components analysed included systolic blood pressure, diastolic blood pressure (DBP) and pulse pressure (PP). The data were analysed to produce summary statistics (mean, median, maximum, minimum). Standard deviation and quartile ranges were also calculated. Median BP and inter-quartile ranges (IQRs) are presented for each analysis as caterpillar plots. In addition, the percentage of HD patients with pre-dialysis systolic $\mathrm{BP}<120 \mathrm{mmHg}$, between $120-160 \mathrm{mmHg}$, >160 mmHg; PD and transplant patients attaining Renal Association standards for $\mathrm{BP}(<\mathbf{1 3 0 / 8 0} \mathbf{m m} \mathbf{H g})$ in individual renal centres and each nation were calculated and are presented with $95 \%$ confidence intervals in caterpillar plots.

Chi-squared tests were used in the analyses of the 2012 BP data to test for statistically significant differences between renal centres and between nations. All statistical analyses were performed using SAS version 9.3.

\section{Results}

\section{Data completeness}

Data extracts were received from all 62 centres in England, Wales and Northern Ireland. Data completeness is summarised in table 11.1. Overall, completeness was very similar to that previously reported.

\section{BP on each modality}

Figure 11.1 gives the median and IQR for SBP, DBP and $\mathrm{PP}$ in prevalent HD patients (pre- and post-dialysis), $\mathrm{PD}$ and transplant patients.

In 2012, the median pre- and post-HD SBPs were $140 \mathrm{mmHg}$ and $128 \mathrm{mmHg}$ respectively. The median
SBP of patients on PD was $137 \mathrm{mmHg}$. Transplant recipients had a median SBP of $134 \mathrm{mmHg}$. Median DBP was $71 \mathrm{mmHg}$ (pre-HD), $67 \mathrm{mmHg}$ (post-HD), $78 \mathrm{mmHg}(\mathrm{PD})$ and $79 \mathrm{mmHg}$ (transplant).

\section{Relationship between the centre mean and the} proportion above a threshold $B P$ in that centre

As the distribution of $\mathrm{BP}$ in each centre approximates a normal distribution (data not shown), the population mean of each BP variable should predict the number of individuals above (or below) a predefined threshold or standard (Rose and Day 1990). As these assumptions were confirmed in the 13th UKRR Annual Report [23] only median BP data by centre are presented below.

\section{Centre-specific analyses of $B P$ in haemodialysis patients}

Figures 11.2 and 11.3 illustrate the median and IQR pre-dialysis SBP and DBP in each centre supplying data on $>50 \%$ of patients. The median HD pre-dialysis SBP and pre-dialysis DBP for the UK were $140 \mathrm{mmHg}$ and $71 \mathrm{mmHg}$ respectively. Figures 11.4 and 11.5 illustrate the equivalent analyses for post-dialysis BP.

There remains marked centre variation. The difference between the centres with the lowest and highest median SBP was $>20 \mathrm{mmHg}$. Comparison with previous UKRR reports showed that in general, the same centres can be found at roughly the same place in the distribution from year to year.

\section{Adherence to guidelines}

Figures 11.6, 11.7 and 11.8 illustrate the percentages (with 95\% confidence intervals (CIs)) of HD patients achieving SBP in the range $120-160 \mathrm{mmHg}$, $<120 \mathrm{mmHg}$ and $>160 \mathrm{mmHg}$ respectively. There was marked variation (45-80\%) between centres achieving their pre-dialysis SBP readings in the range 120$160 \mathrm{mmHg}$. The vast majority of centres had greater than $50 \%$ of their patients falling in the range 120 $160 \mathrm{mmHg}$. Thirty-five of the centres had greater than $20 \%$ of their patients with a pre-dialysis SBP $<120 \mathrm{mmHg}$ and there were also 35 centres who had greater than $20 \%$ of their patients with a pre-dialysis SBP $>160 \mathrm{mmHg}$.

\section{Centre-specific analyses of BP in peritoneal dialysis patients}

Figures 11.9 and 11.10 illustrate the median and IQR SBP and DBP in each centre supplying data on $>50 \%$ of eligible patients. Figure 11.11 gives the percentage of 
Table 11.1. Percentage of patients by renal centre for whom BP readings were received by the UKRR, by modality

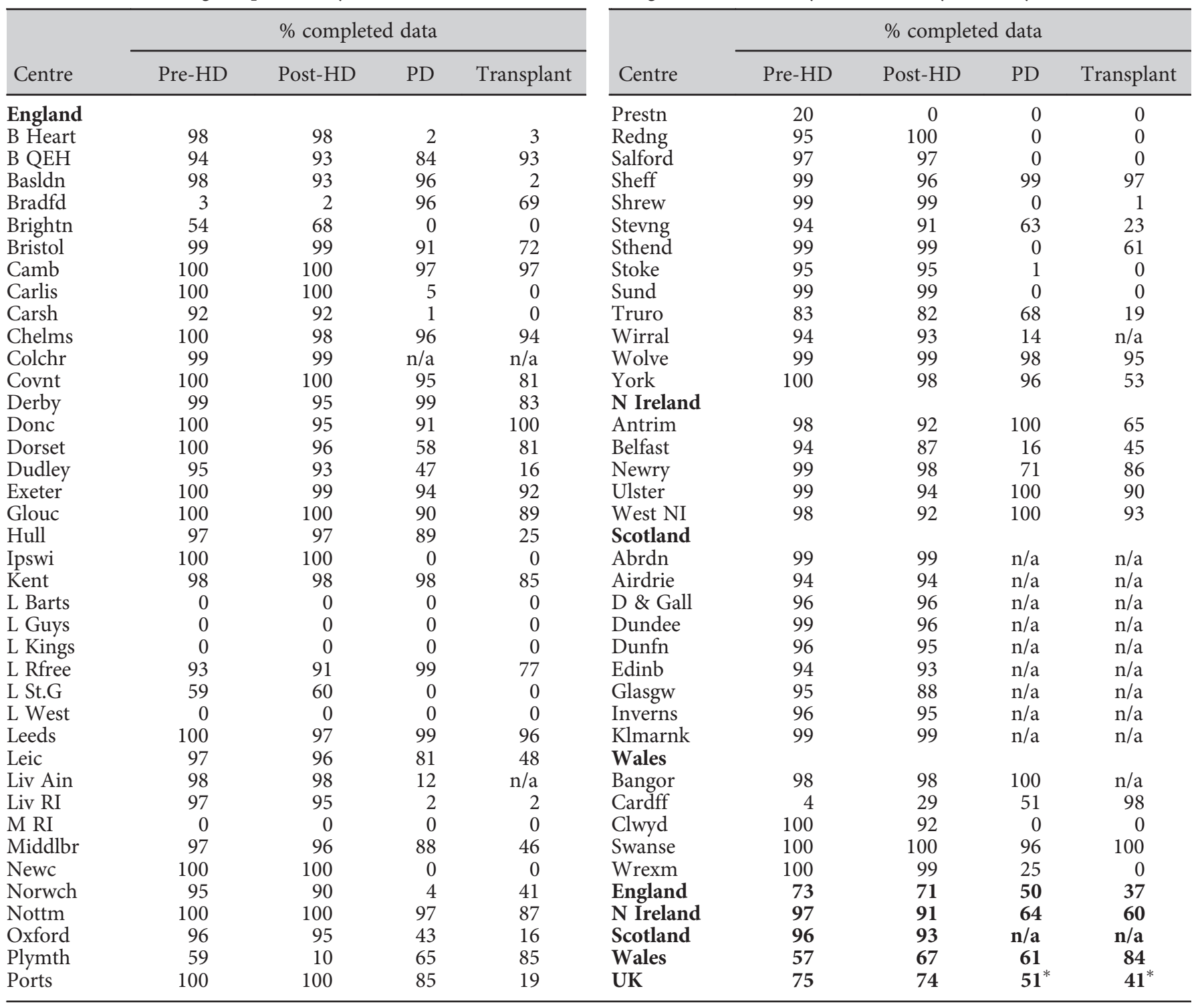

*UK \% completeness for PD and transplant excludes Scotland

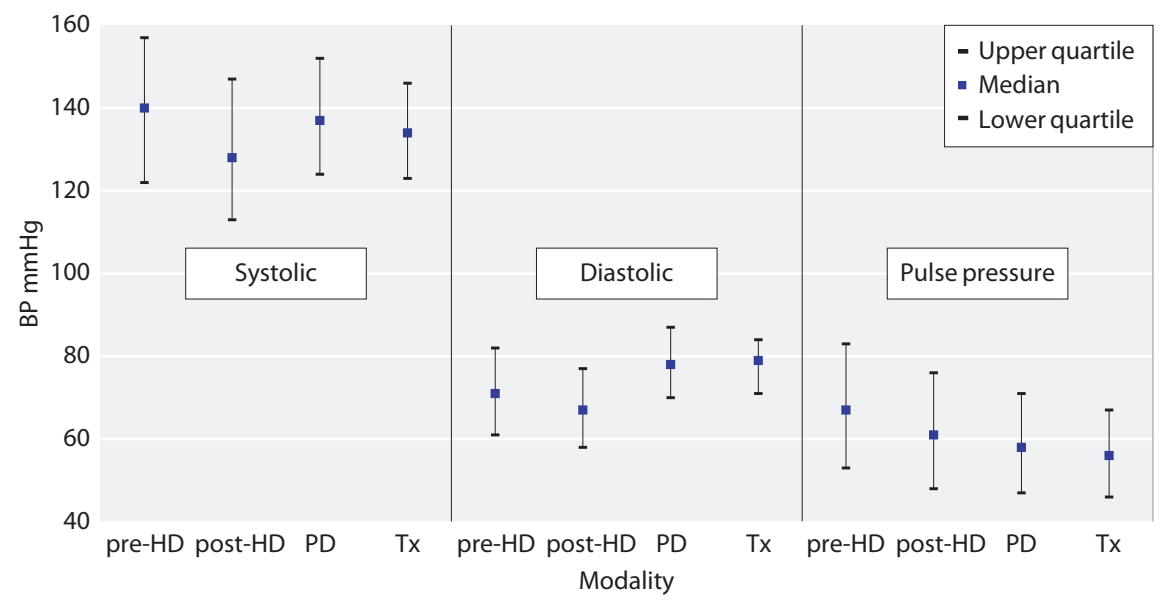

Fig. 11.1. Summary of BP achievements 


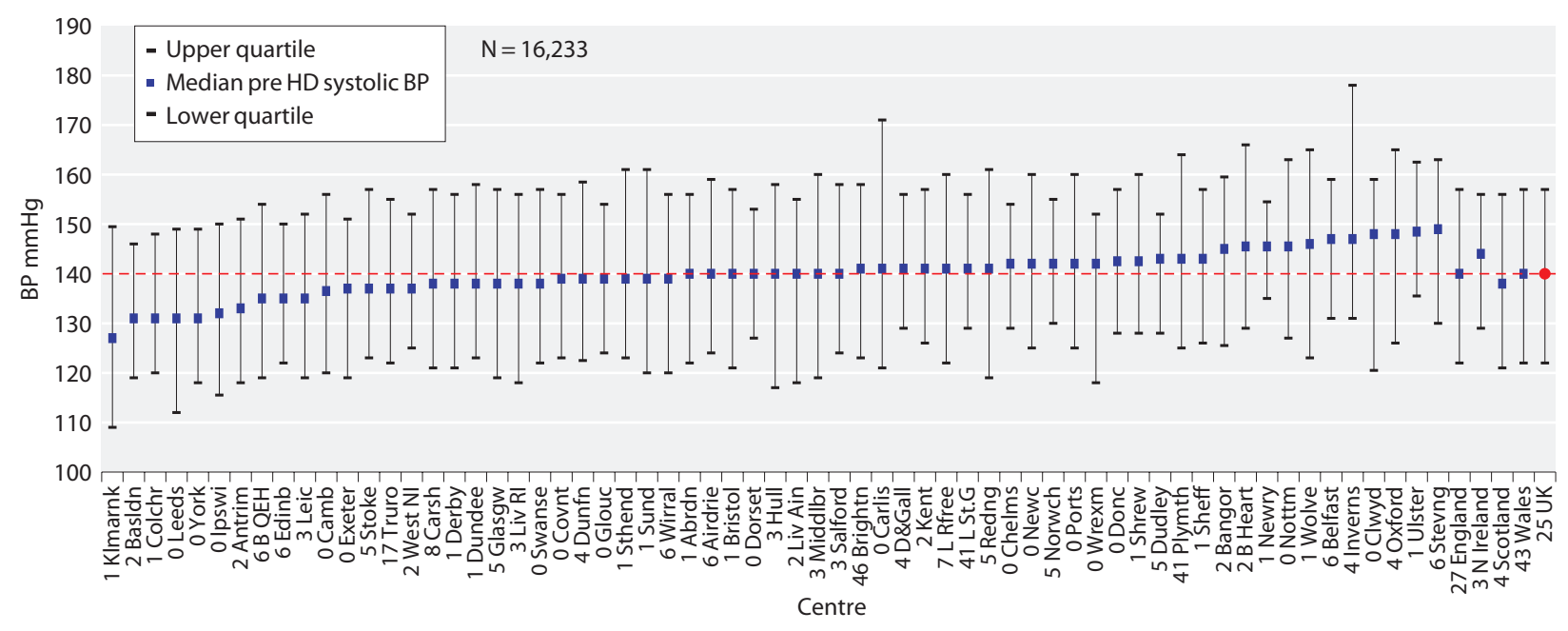

Fig. 11.2. Median systolic BP: pre-HD

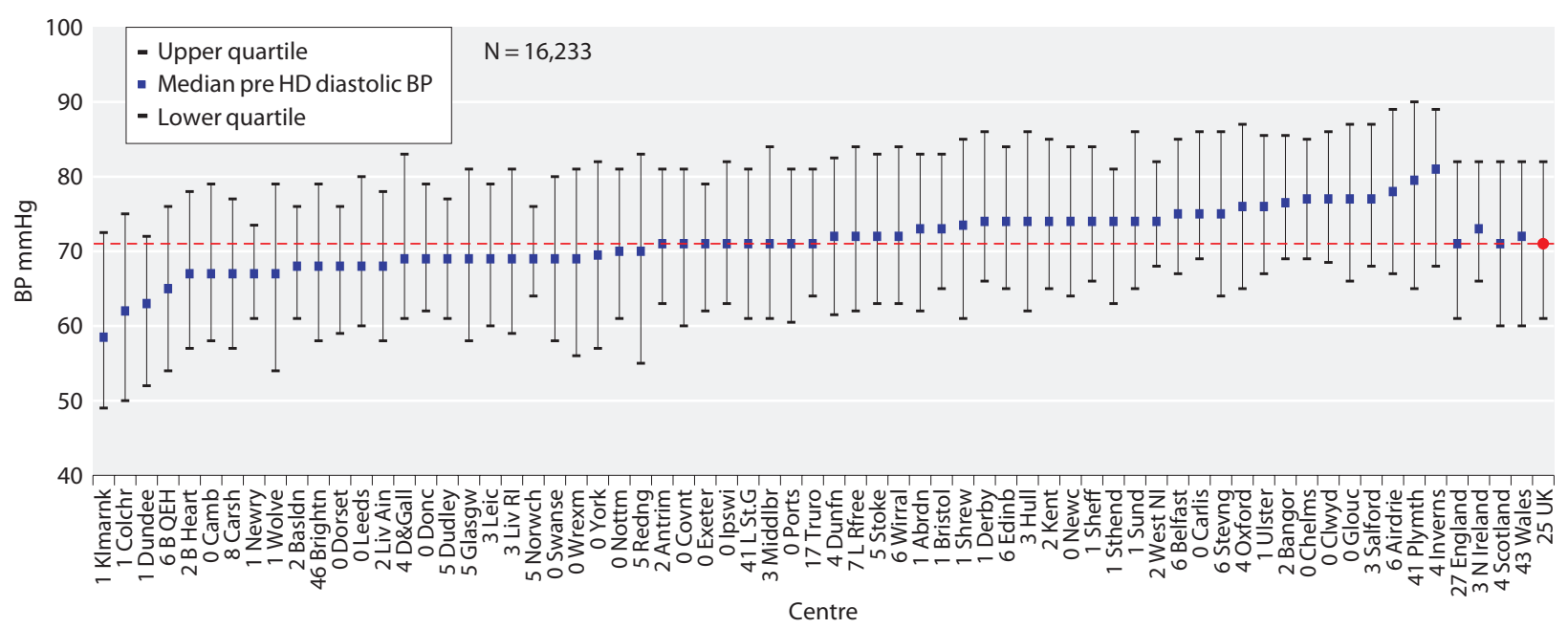

Fig. 11.3. Median diastolic BP: pre-HD

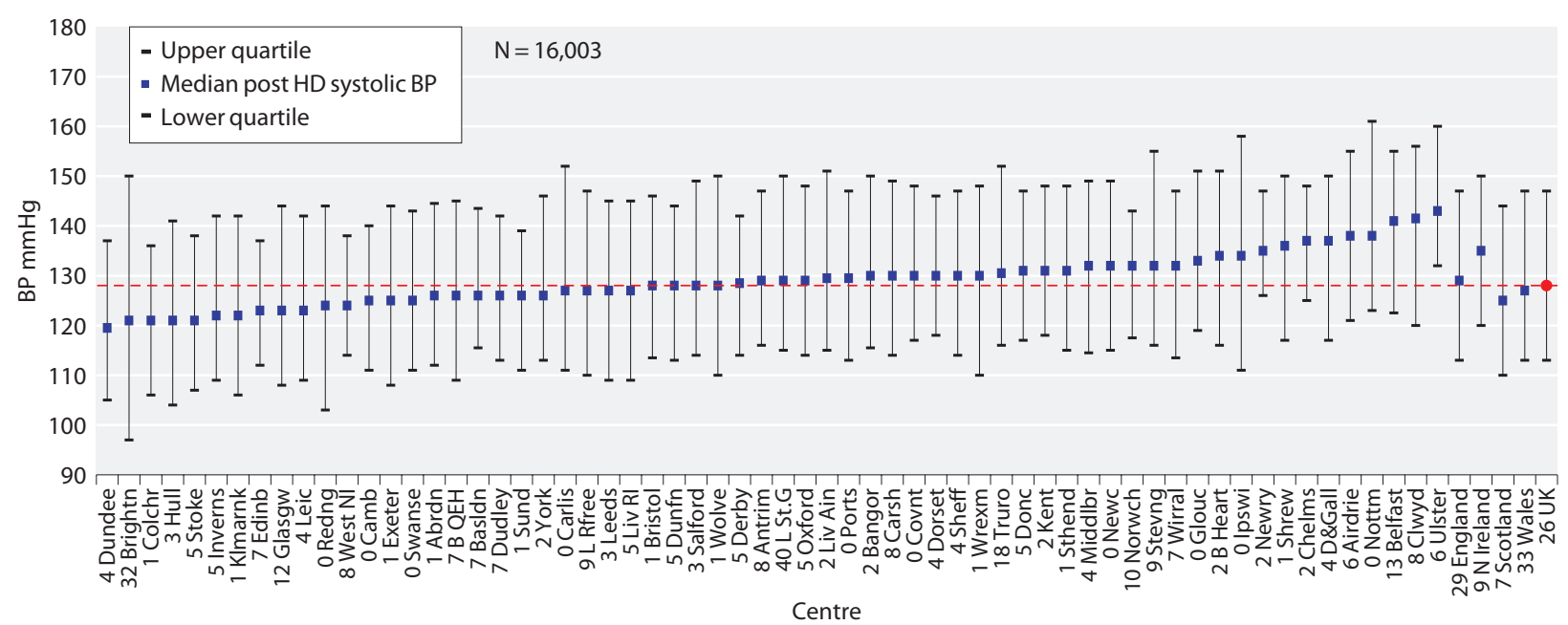

Fig. 11.4. Median systolic BP: post-HD 


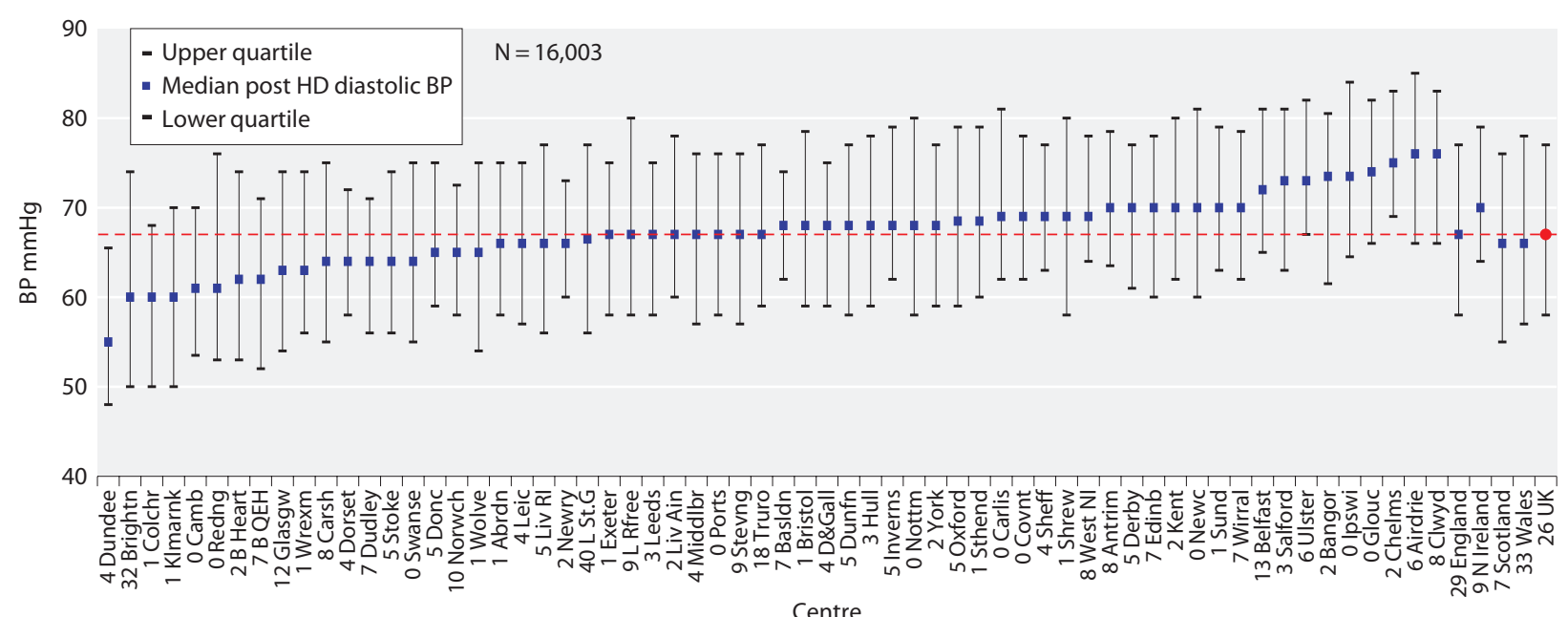

Fig. 11.5. Median diastolic BP: post-HD

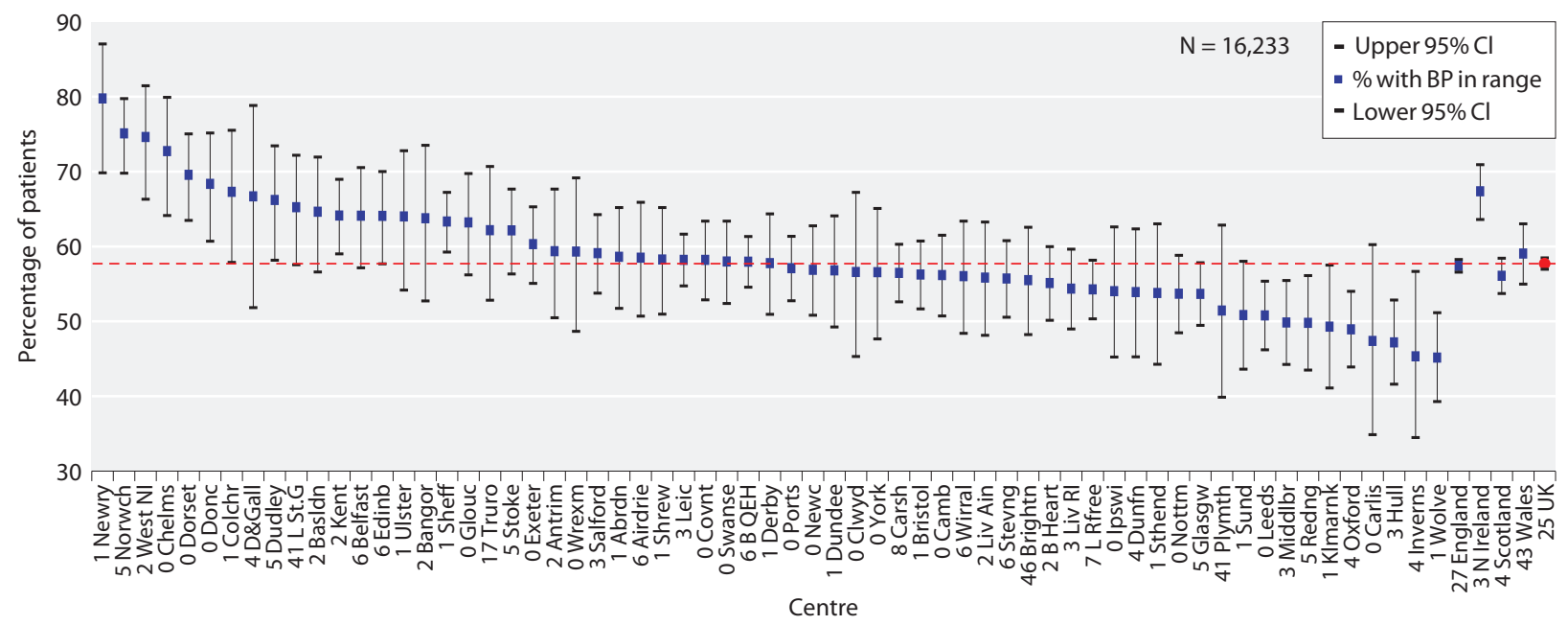

Fig 11.6. Percentage of patients achieving pre-dialysis SBP readings in the range $120-160 \mathrm{mmHg}$

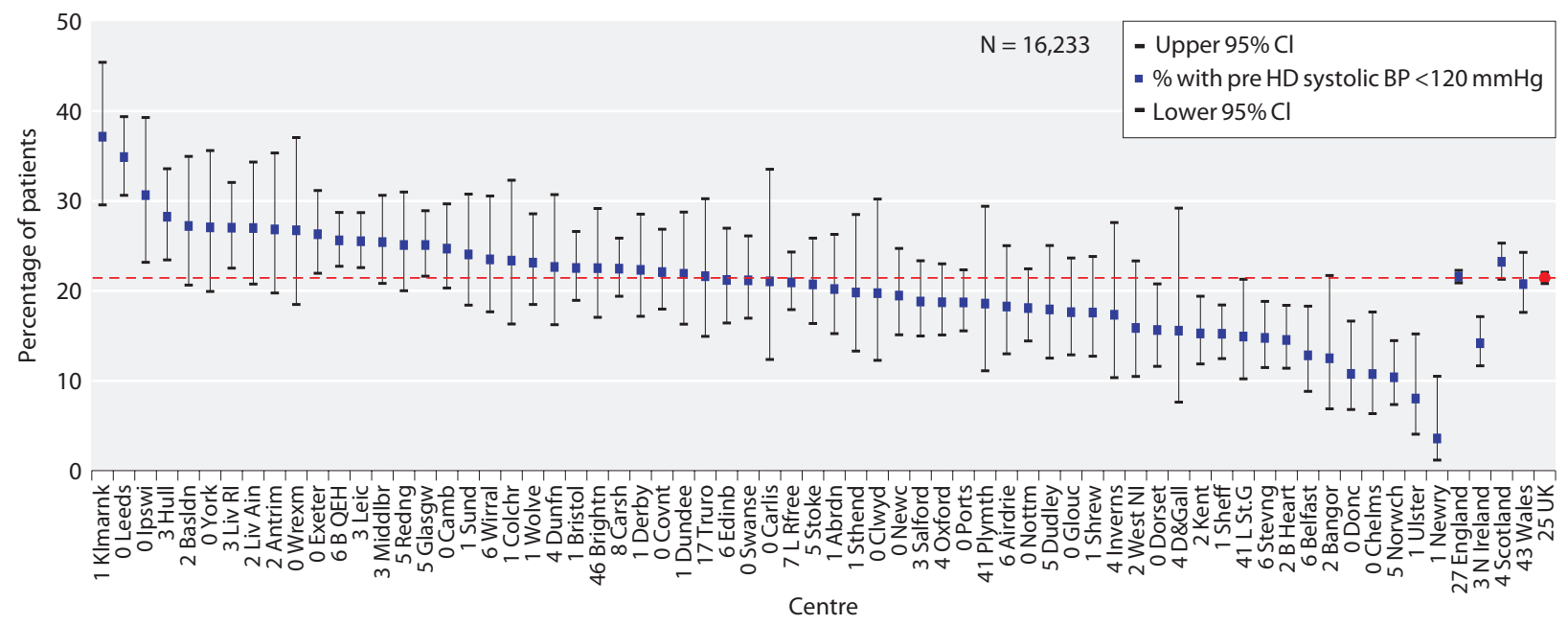

Fig 11.7. Percentage of patients with pre-dialysis $\mathrm{SBP}<120 \mathrm{mmHg}$ 


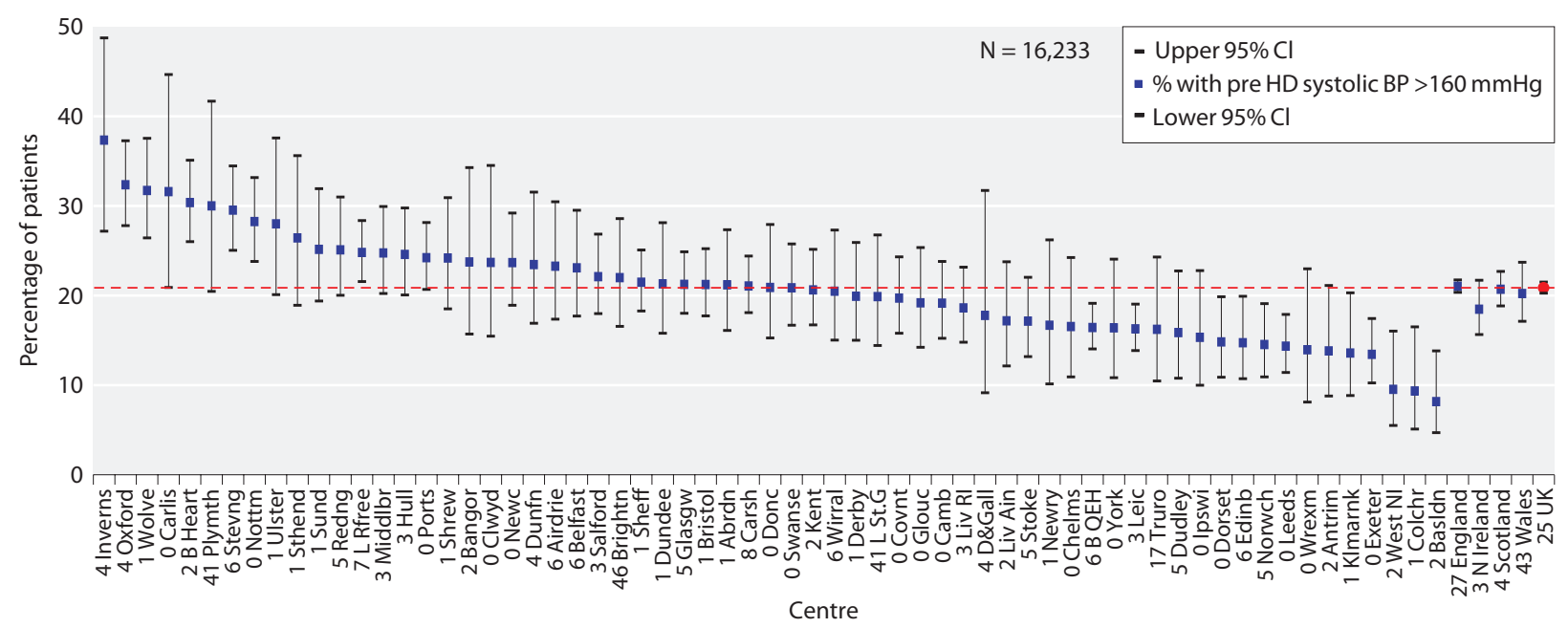

Fig 11.8. Percentage of patients with pre-dialysis SBP $>160 \mathrm{mmHg}$

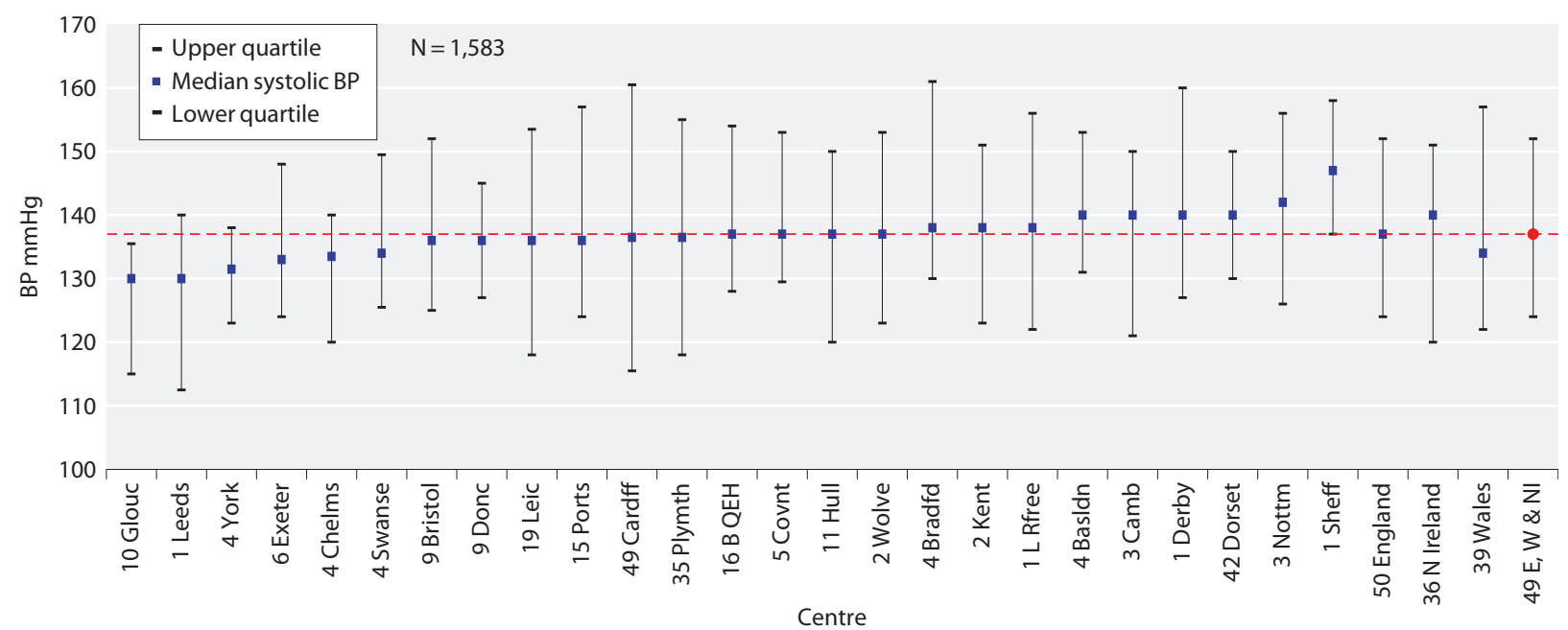

Fig. 11.9. Median systolic BP: PD

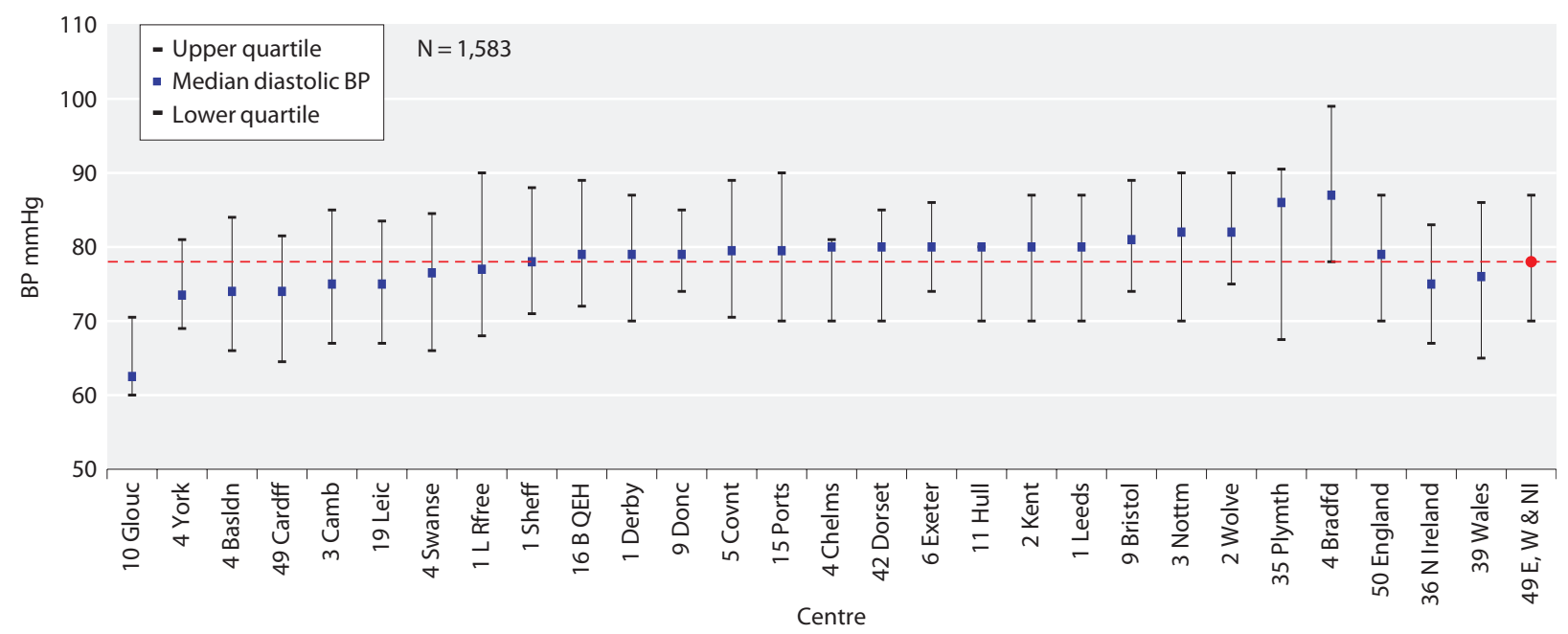

Fig. 11.10. Median diastolic BP: $\mathrm{PD}$ 


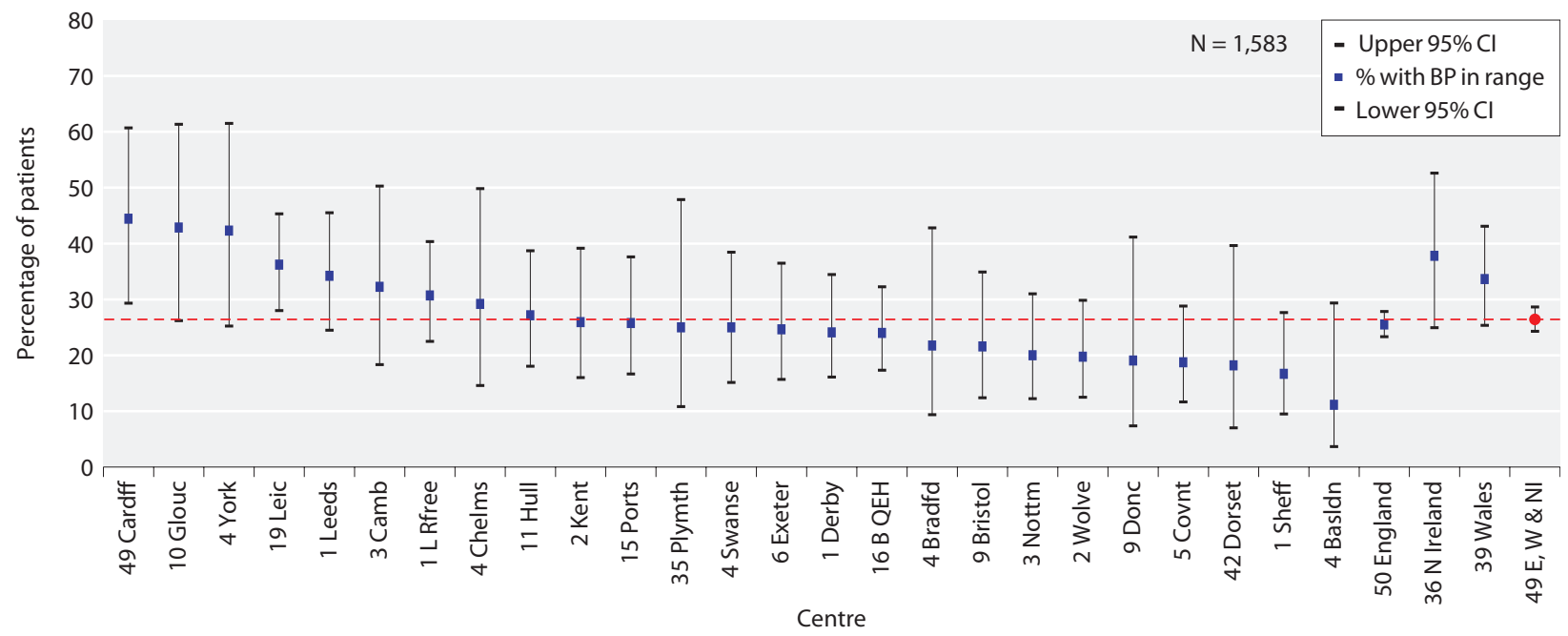

Fig. 11.11. Percentage of patients with $\mathrm{BP}<130 \mathrm{mmHg}$ systolic and $<80 \mathrm{mmHg}$ diastolic: $\mathrm{PD}$

patients meeting the audit standard of $\mathrm{BP}<130 /$ $80 \mathrm{mmHg}$.

The possibility of information bias in these analyses cannot be excluded since BP data are extracted from the routine clinical record.

Centre-specific analysis of $B P$ in transplant patients

Figures 11.12 and 11.13 illustrate the median and IQR SBP and DBP in each centre supplying data on $>50 \%$ of eligible patients and figure 11.14 illustrates the percentage of patients meeting the audit standard of $\mathrm{BP}<130$ / $80 \mathrm{mmHg}$.

As with PD patients, the possibility of information bias in these analyses cannot be excluded.

\section{Discussion}

Blood pressure control amongst HD patients in the UK remained poor in 2012. Nearly half of centres had greater than $20 \%$ of their patients with pre-dialysis systolic $\mathrm{BP}<120 \mathrm{mmHg}$. There were also nearly half who had greater than $20 \%$ of their patients with pre-dialysis systolic BP $>160 \mathrm{mmHg}$. There continues to be marked variation between centres in attainment of nationally agreed BP standards for those on PD and those with functioning kidney transplants.

High BP is common in HD patients and contributes to the observed excess of cardiovascular morbidity and mortality in these patients [24]. However, there is still

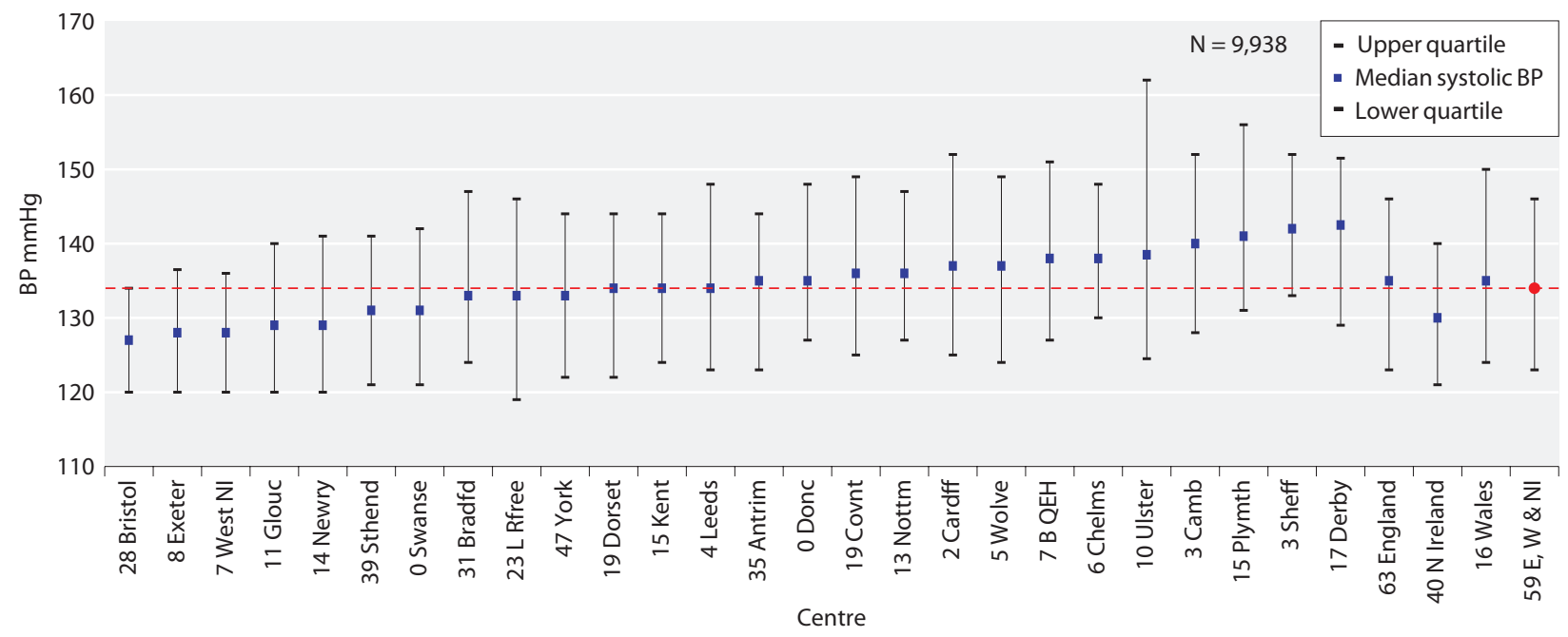

Fig. 11.12. Median systolic BP: transplant 


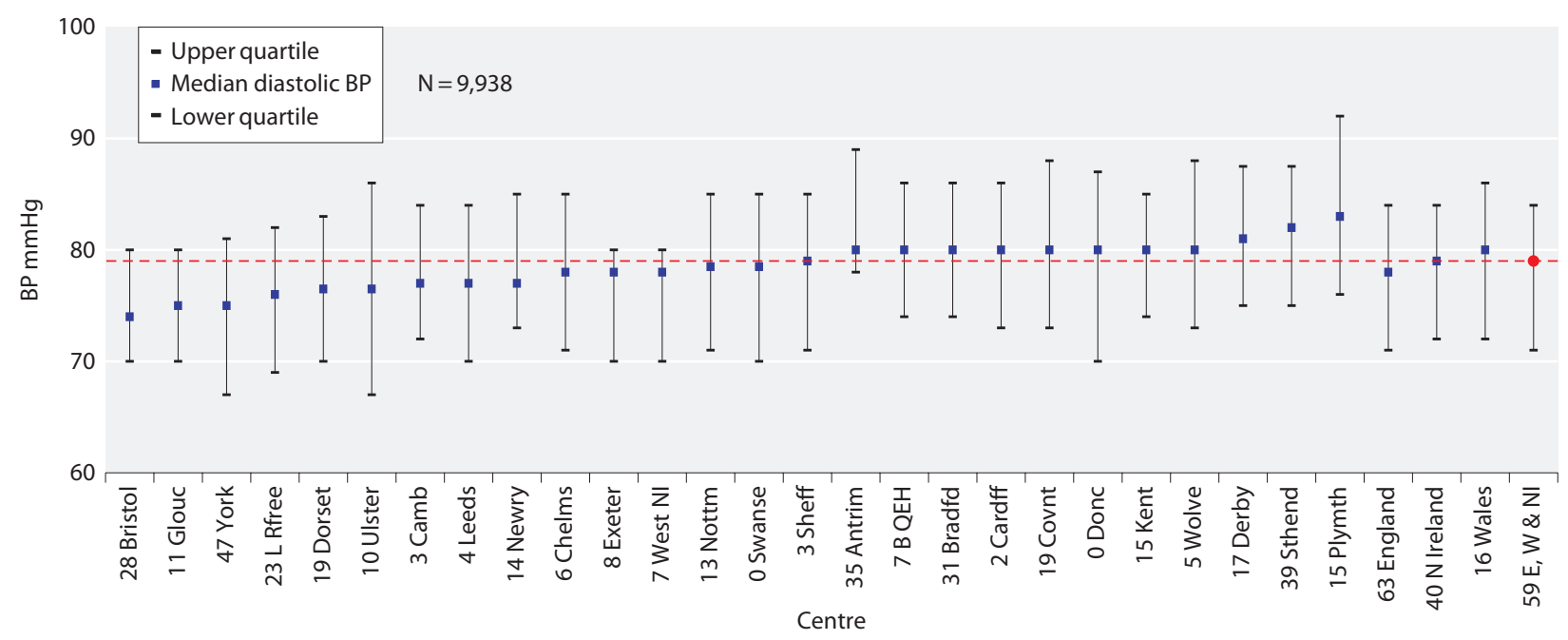

Fig. 11.13. Median diastolic BP: transplant

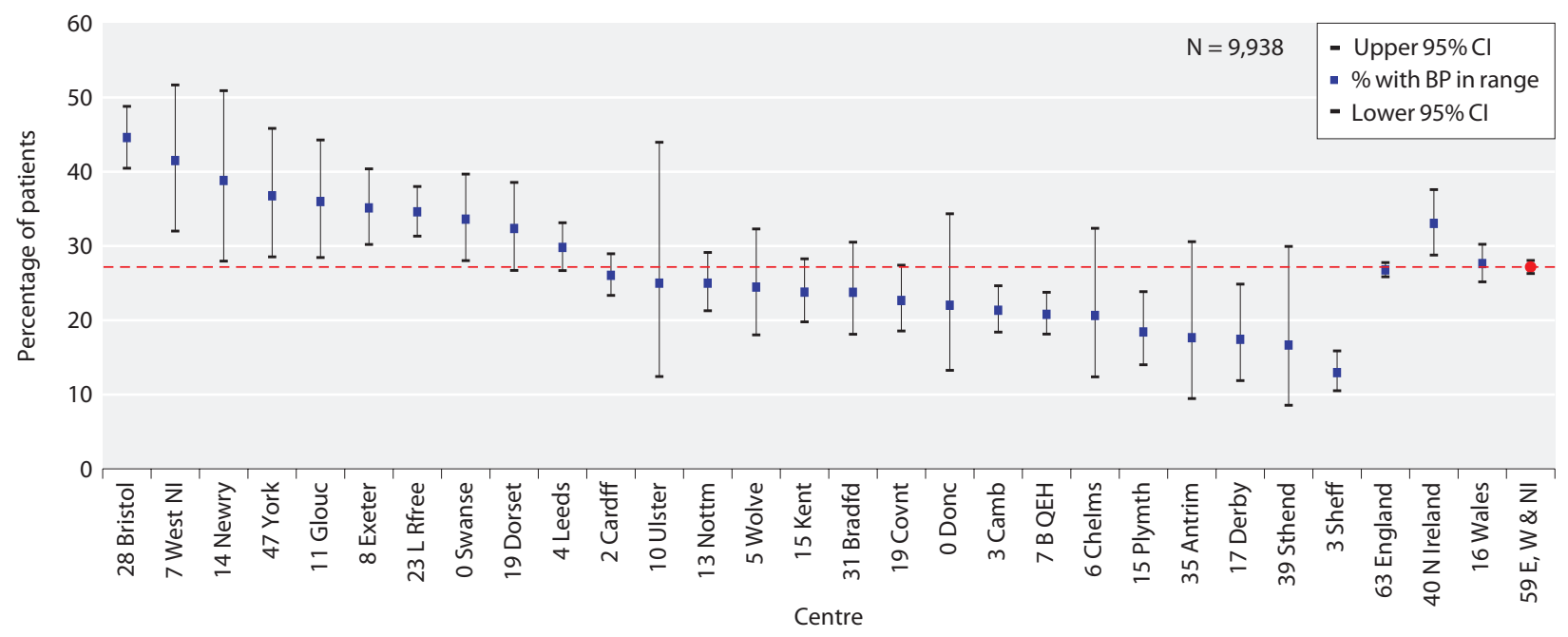

Fig. 11.14. Percentage of patients with $\mathrm{BP}<130 \mathrm{mmHg}$ systolic and $<80 \mathrm{mmHg}$ diastolic: transplant

no clarity about how and when to measure BP, or about $\mathrm{BP}$ targets in the haemodialysis population.

Reliance upon immediate pre-dialysis and/or postdialysis BP measurements alone to detect hypertension in patients undergoing haemodialysis may be misleading [25]. Pre-dialysis BP may substantially overestimate mean ambulatory inter-dialytic BP [26]. For pre-dialysis SBP the overestimate may range from $6-18 \mathrm{mmHg}$ depending on the timing of the measurement and for DBP from 3-9 mmHg. In contrast, post-dialysis measurements underestimate mean systolic BP by approximately $4-14 \mathrm{mmHg}$ for SBP and $1 \mathrm{mmHg}$ for DBP. There are suggestions that post-dialysis BP may be more reflective of mean inter-dialytic BP $[25,26]$.
The utility of UKRR data could be enhanced by collection of data on intra-dialytic weight gain, the use of BP lowering drugs and the frequency of intra-dialytic hypotension. Future registry analyses should include systolic BP as an independent risk factor in models for predictors of death and variation in survival on dialysis.

Conflicts of interest: none

\section{References}

Kalantar-Zadeh K KR, Kopple JD. Reverse epidemiology of blood pressure in dialysis patients. Kidney Int. 2005;67(5):2067 
$\checkmark 2$ Levin NW, Kotanko P, Eckardt KU, Kasiske BL, Chazot C, Cheung AK, Redon J, Wheeler DC, Zoccali C, London GM: Blood pressure in chronic kidney disease stage 5D-report from a Kidney Disease: Improving Global Outcomes controversies conference. Kidney Int. 2010;77:273-28

3 Robinson BM TL, Zhang J, Wolfe RA, Goodkin DA, Greenwood RN, Kerr PG, Morgenstern H, Li Y, Pisoni RL, Saran R, Tentori F, Akizawa T, Fukuhara S, Port FK. Blood pressure levels and mortality risk among hemodialysis patients in the Dialysis Outcomes and Practice Patterns Study. Kidney Int 2012;82(5):570-580

4 Chazot C, Vo-Van C, Deleaval P, Lorriaux C, Hurot JM, Mayor B, Jean G: Predialysis systolic blood pressure evolution in incident hemodialysis patients: effects of the dry weight method and prognostic value. Blood Purif. 2012;33:275-283

5 The FHN Trial Group. In-Center Hemodialysis Six Times per Week versus Three Times per Week. New England Journal of Medicine. 2010; 363:2287-2300

6 Krapf R, Hulter HN. Arterial Hypertension Induced by Erythropoietin and Erythropoiesis-Stimulating Agents (ESA). Clinical Journal of the American Society of Nephrology 2009;4(2):470-480

$\checkmark 7$ Oberbauer R, Kreis H, Johnson RW, Mota A, Claesson K, Ruiz JC, Wilczek H, Jamieson N, Henriques AC, Paczek L, Chapman J, Burke JT: Rapamune Maintenance Regimen Study Group: Long-term improvement in renal function with sirolimus after early cyclosporine withdrawal in renal transplant recipients: 2-year results of the Rapamune Maintenance Regimen Study. Transplantation 2003;76:364-370

$\checkmark 8$ Rohrscheib MR, Myers OB, Servilla KS, Adams CD, Miskulin D, Bedrick EJ, Hunt WC, Lindsey DE, Gabaldon D, Zager PG: Age-related blood pressure patterns and blood pressure variability among hemodialysis patients. Clin J Am Soc Nephrol 2008;3:1407-1414

$\checkmark 9$ Di Iorio B DML, Torraca S, Sirico ML, Guastaferro P, Chiuchiolo L, Nigro F, De Blasio A, Romano P, Pota A, Rubino R, Morrone L, Lopez T, Casino FG. Variability of blood pressure in dialysis patients: a new marker of cardiovascular risk. J Nephrol 2013;26(1):173-182

10 Agarwal R. Blood pressure and mortality among hemodialysis patients. Hypertension 2010;55(3):762-768

11 Zoccali C. Arterial pressure components and cardiovascular risk in endstage renal disease. Nephrol. Dial. Transplant. 2003 Feb;18(2):249-252

-12 Mazzuchi N, Carbonell E, Fernández-Cean J. Importance of blood pressure control in hemodialysis patient survival. Kidney Int. 2000 Nov;58(5):2147-2154

$>13$ Tomita J, Kimura G, Inoue T, Inenaga T, Sanai T, Kawano Y, et al. Role of systolic blood pressure in determining prognosis of hemodialyzed patients. Am. J. Kidney Dis. 1995 Mar;25(3):405-412
14 Li Z, Lacson E, Lowrie EG, Ofsthun NJ, Kuhlmann MK, Lazarus JM, et al. The epidemiology of systolic blood pressure and death risk in hemodialysis patients. Am. J. Kidney Dis. 2006 Oct;48(4):606-615

15 Davenport A, Cox C, Thuraisingham R. Achieving blood pressure targets during dialysis improves control but increases intradialytic hypotension. Kidney Int. 2008 Mar;73(6):759-764

16 Shoji T, Tsubakihara Y, Fujii M, Imai E. Hemodialysis-associated hypotension as an independent risk factor for two-year mortality in hemodialysis patients. Kidney Int. 2004 Sep;66(3):1212-1220

17 Burton JO, Jefferies HJ, Selby NM, McIntyre CW. Hemodialysis-induced cardiac injury: determinants and associated outcomes. Clin J Am Soc Nephrol. 2009 May;4(5):914-920

18 Zager PG, Nikolic J, Brown RH, Campbell MA, Hunt WC, Peterson D, et al. "U" curve association of blood pressure and mortality in hemodialysis patients. Medical Directors of Dialysis Clinic, Inc. Kidney Int. 1998 Aug;54(2):561-569

19 Holt S, Goldsmith D: UK Renal Association Clinical Practice Guidelines Committee: 2010 RA Guidelines - Cardiovascular disease in CKD, 5th Edition. 2010. http://www.renal.org/Clinical/GuidelinesSection/ CardiovascularDiseaseInCKD.aspx

20 Levin NW, Kotanko P, Eckardt KU, et al. Blood pressure in chronic kidney disease stage 5D-report from a Kidney Disease: Improving Global Outcomes controversies conference. Kidney Int 2010;77(4):273-284

21 KDIGO clinical practice guideline for the care of kidney transplant recipients. Am J Transplant 2009;9(suppl 3):S1-155

22 Ansell D, Tomson CR. UK Renal Registry 11th Annual Report (December 2008): Chapter 15 The UK Renal Registry, UKRR database, validation and methodology. Nephron Clin Pract 2009;111(suppl 1): c277-285

23 Webb L, Tomson CRV, Casula A, Farrington K: Registry 13th Annual Report (December 2010): Chapter 11 Blood Pressure Profile of Prevalent Patients receiving Renal Replacement Therapy in England, Wales and Northern Ireland in 2009: National and Centre-Specific Analyses. Nephron Clin Pract 2011;119(suppl 2):c215-c224

$\checkmark 24$ Foley RN, Parfrey PS, Harnett JD, Kent GM, Murray DC, Barre PE: Impact of hypertension on cardiomyopathy, morbidity and mortality in end-stage renal disease. Kidney Int 1996;49:1379-1385

25 Agarwal R, Peixoto, AJ, Santos SFF, Zoccali C. Pre- and post-dialysis blood pressures are imprecise estimates of interdialytic ambulatory blood pressure. Clin J Am Soc Nephrol 2006;1:389-398

26 Mitra S, Chandna SM, Farrington K. What is hypertension in chronic haemodialysis? The role of interdialytic blood pressure monitoring. Nephrol Dial Transplant. 1999;14(12):2915-21 